\title{
A NR31 E O USO DO EPI NA CAFEICULTURA DO MUNICÍPIO DE RIBEIRÃO CORRENTE-SP: IMPRESSÕES DO PRODUTOR E DO TRABALHADOR RURAL
}

\author{
OLIVEIRA, Lucas Lancha Alves de ${ }^{1}$
}

SEGATO, Silvelena Vanzolini ${ }^{2}$

\begin{abstract}
RESUMO: A Norma Regulamentadora no. 31, estabelecida pela Portaria no. 86 de 03 de março de 2005, do Ministério do Trabalho e Emprego dispõe sobre como deve ser o ambiente de trabalho e a segurança dos trabalhadores rurais e impõe quase que exclusivamente as obrigações em cumprir essa norma aos produtores rurais. Esse trabalho pretende aferir como a norma é entendida e aplicada tanto pelos proprietários quanto pelos trabalhadores rurais. Foram aplicados questionários com abordagem qualitativa e quantitativa. Conclui-se que para o município de Ribeirão Corrente (SP) é grande o desconhecimento da NR31 nas propriedades rurais e baixo o uso de EPI.
\end{abstract}

Palavras-chave: Café. Segurança no trabalho rural. Legislação rural. Periculosidade e insalubridade.

SUMMARY: The Regulatory Norm No. 31 established by the Decree No. 86 of 3 March 2005, from the Ministry of Labor and Employment, provides on how the work environment and farmers' safety should be and imposes, almost exclusively, obligations to fulfilling this norm to farmers. This study aimed to assess how the norm is understood and applied by both the landowners and the rural workers. Questionnaires with qualitative and quantitative approach were applied. The results were presented and analyzed here. In a summary for the city of Ribeirão Corrente (SP) the usage of EPI is low and large the unknowledge of the NR31 at rural properties.

Keywords: Coffee. Risk during work. Rural labor Law. Unhealthiness

\section{INTRODUÇÃO}

O Brasil é o maior produtor de café do mundo, possuindo cafés que atendem todo tipo de mercado consumidor.

A colheita é a operação que mais onera o custo de produção do café. Como a colheita mecânica reduz o custo final do produto, vem ganhando espaço no cenário nacional, principalmente no estado de São Paulo. Contudo, mesmo a colheita mecanizada exige a presença dos trabalhadores rurais nessa operação.

Para garantir um ambiente de trabalho seguro, foram criadas no Brasil as Normas Regulamentadoras, ou NRs, relativas à segurança e medicina do trabalho. Essas normas são de observância obrigatória pelas empresas privadas e públicas, bem como pelos órgãos dos Poderes Legislativo e Judiciário que possuam empregados regidos pela Consolidação das Leis do Trabalho (CLT) (GUIA TRABALHISTA, 2011).

A Norma Regulamentadora de Segurança e Saúde no Trabalho na Agricultura, Pecuária, Silvicultura, Exploração Florestal e Aqüicultura (NR 31), publicada em março de 2005, têm por objetivo estabelecer os preceitos a serem observados na organização e no ambiente de trabalho, de forma a tornar compatível o planejamento e o desenvolvimento dessas atividades (CONTAG, 2011).

Essa Norma Regulamentadora (NR 31) dispõe sobre como deve ser o ambiente de trabalho e a

\footnotetext{
${ }^{1}$ Graduando em Agronomia da FAFRAM, Ituverava, SP.

2 Professor Doutor da Faculdade de Agronomia "Dr. Francisco Maeda"- FAFRAM/FE, Ituverava,SP e do Centro Universitário Moura Lacerda - CUML, Ribeirão Preto, SP. E-mail: sv.segato@ bol.com.br
} 
segurança dos trabalhadores rurais e impõe quase que exclusivamente as obrigações em cumprir essa norma aos produtores rurais. Contudo muitos produtores não conseguem motivar seus empregados no cumprimento dessa norma e reclamam dos custos advindos da NR31. De acordo com Carvalho e Queiroz Neto (2006) o Ministério do Trabalho e Emprego adota normas, como a NR 31, cujo nível de exigência e excessiva burocracia afastam os empreendedores rurais do interesse em contratar novos empregados.

Segundo Yoneya (2008) dentre as exigências legais constam: i. Registro: Todos os funcionários (fixos e temporários) devem ter carteira assinada; ii. Instalações: os banheiros devem ser separados por sexo e a proporção é de um chuveiro para cada 20 empregados e um banheiro para cada 10 funcionários. $\mathrm{O}$ refeitório, coberto, deve ter mesas e cadeiras. $\mathrm{O}$ empregador deve fornecer marmita térmica e água potável; iii. EPI: o empregador deve fornecer equipamentos de proteção individual e exigir seu uso pelo funcionário; iv. Transporte: o veículo deve ser autorizado por órgão competente e o motorista, habilitado. Os passageiros devem ser transportados sentados, com cinto de segurança; as ferramentas devem ficar em compartimento apropriado no veículo. O nível de exigência da NR 31 pode, inclusive, acelerar o processo de mecanização do trabalho no campo, servindo de estímulo à aquisição de colhedoras capazes de substituir o trabalho de 120 homens por dia. O investimento para aquisição de um lote de três destas máquinas exige investimentos da ordem de $\mathrm{R} \$ 300$ mil por máquina (CARVALHO; QUEIROZ NETO, 2006).

A NR 31 também impõe obrigações aos trabalhadores rurais, como o cumprimento das determinações sobre as formas seguras de desenvolver suas atividades, adoção de medidas de proteção determinadas pelo empregador (sob pena de constituir ato faltoso a recusa injustificada), submeter-se aos exames médicos previstos na NR e colaborar com a empresa na aplicação da mesma (DINAMARCO, 2005).

Essa pesquisa foi conduzida com vistas a conhecer um pouco da realidade enfrentada pelos produtores e trabalhadores rurais no cumprimento das exigências da NR31, no município de Ribeirão Corrente/SP, situado no interior do Estado de São Paulo, sendo que a cultura de café é predominante. A dificuldade de implantação e manutenção da NR31 chamou a atenção levantando um questionamento: "Por que é tão difícil conscientizar os trabalhadores rurais a colaborar com os produtores?"

Assim, o presente trabalho teve por objetivo verificar se produtores e trabalhadores rurais conhecem a Norma Regulamentadora (NR) 31, se os trabalhadores rurais utilizam os EPI's (equipamentos de proteção individual) exigidos por ela, e levantar as possíveis dificuldades na implantação e manutenção da NR31 nas propriedades produtoras de café do município de Ribeirão Corrente, SP.

\section{MATERIAL E MÉTODOS}

A pesquisa foi alicerçada na discussão da NR31 com os produtores e com os trabalhadores rurais.

No município de Ribeirão Corrente existem 374 propriedades rurais sendo 275 produtoras de café (SÃO PAULO, 2008). O número de trabalhadores nestas propriedades foi estimado em torno de 500. Não existe uma fonte oficial constatando estes dados.

Os questionários foram aplicados a 70 trabalhadores (cerca de 14\% do total) em 37 propriedades (mais de 13\% do total). A aplicação dos questionários foi feita diretamente pelo pesquisador entre os dias 08 de agosto de 2010 até 15 de abril de 2011.

Os trabalhadores responderam às perguntas em meio a uma pausa do trabalho, ali mesmo no campo. A cada entrevistado foi feita uma explanação geral dos motivos e, muito importante para o propósito da pesquisa, foi que todos concordaram em participar.

O próprio pesquisador preencheu os questionários observando rigorosamente as respostas do 
entrevistado e se mantendo neutro diante das respostas com o objetivo de garantir a fidelidade das informações recebidas. Da mesma forma foi feita a entrevista ao produtor.

A pesquisa de campo contou com visitas nas lavouras, conversas informais com os produtores, trabalhadores e levantamento de dados feito por meios da aplicação de questionários. Assim, elaborou-se uma ficha diagnóstica com ajuda do sindicato, de psicólogo e de técnico de segurança no trabalho. Dessa maneira, foi possível conhecer dados mais objetivos relativos às dificuldades na aplicabilidade da NR31 na visão do produtor e do trabalhador rural.

Os questionários preparados foram inicialmente submetidos a um produtor rural, os problemas percebidos foram solucionados e, em seguida, procedeu-se à aplicação junto a proprietários da região de Ribeirão Corrente (SP), de pequeno, médio e grande porte.

A amostra de propriedades avaliadas foi superior a $13 \%$. No município existem $2,6 \%$ de grandes propriedades, $22,54 \%$ de médias e $74,86 \%$ de pequeno porte. Aqui se refere à totalidade das propriedades. Segundo o STF, Lei $n^{\circ}$ 4.504/1964: pequena propriedade até 4 módulos fiscais, média superior a quatro e até 15 módulos fiscais e grande propriedade acima de 15 módulos fiscais. O módulo fiscal varia com o município, no caso de Ribeirão Corrente é de 16 hectares (Newton R. - EDR/CA de Franca 15/06/2011 Fonte SAA (SÃO PAULO, 2008).

Os dados obtidos foram tabulados para análise e discussão e os mais relevantes são apresentados.

\section{RESULTADOS E DISCUSSÃO}

\section{Segmento dos trabalhadores}

As Figuras seguintes (1 a 7) registram os resultados obtidos a partir de entrevistas realizadas junto a trabalhadores rurais de Ribeirão Corrente (SP).

a) Questão 1. Tem registro em carteira? Pela amostra (Figura 1) de cerca de $14 \%$ dos trabalhadores do município pouco mais que a metade dos trabalhadores rurais possui carteira assinada $(57,1 \%)$, denotando que ainda parte dos trabalhadores não se beneficia de tal registro e estão ilegais, ou seja, grande parte dos trabalhadores trabalha de maneira informal. $\mathrm{Na}$ fiscalização, o primeiro item verificado é se os funcionários, sobretudo os safristas, estão com o registro em carteira em dia, normalmente o safrista não quer ser registrado para não perder a mobilidade de poder ir trabalhar na fazenda vizinha, caso a remuneração seja melhor, de acordo com Yoneya (2008).

Figura 1. Porcentagem de trabalhadores rurais amostrados em cafezais do município de Ribeirão Corrente, SP, com ou sem registro em carteira de trabalho.

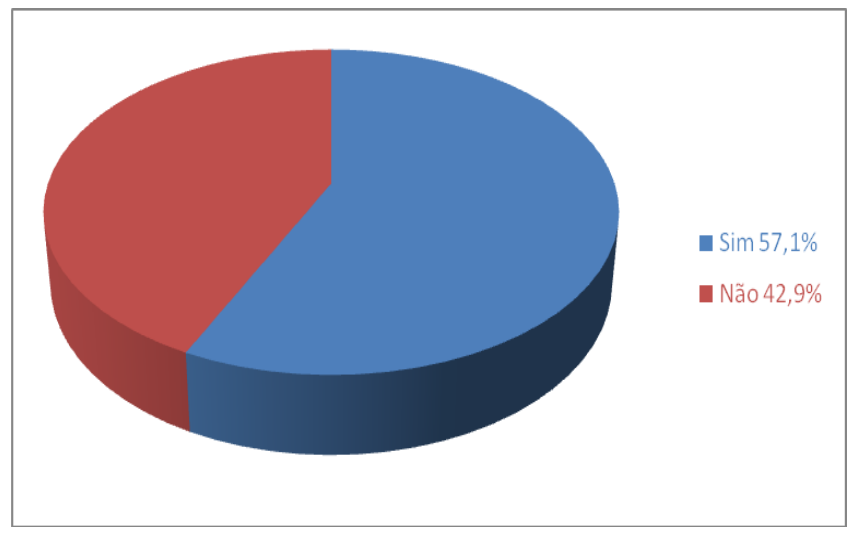

Fonte: Elaborado pelo Autor 
b) Questão 2. Na sua função, você é orientado para usar equipamentos de proteção individual (EPIs)? O entrevistado deveria responder objetivamente sim ou não. Uma grande parte, 42,9\% respondeu negativamente. Portanto, falta orientação por parte do empregador enfatizando a importância do uso de EPIs.

Figura 2. Porcentagem de trabalhadores rurais amostrados em cafezais do município de Ribeirão Corrente, SP que é ou não orientado sobre o uso de equipamentos de proteção individual (EPI’s).

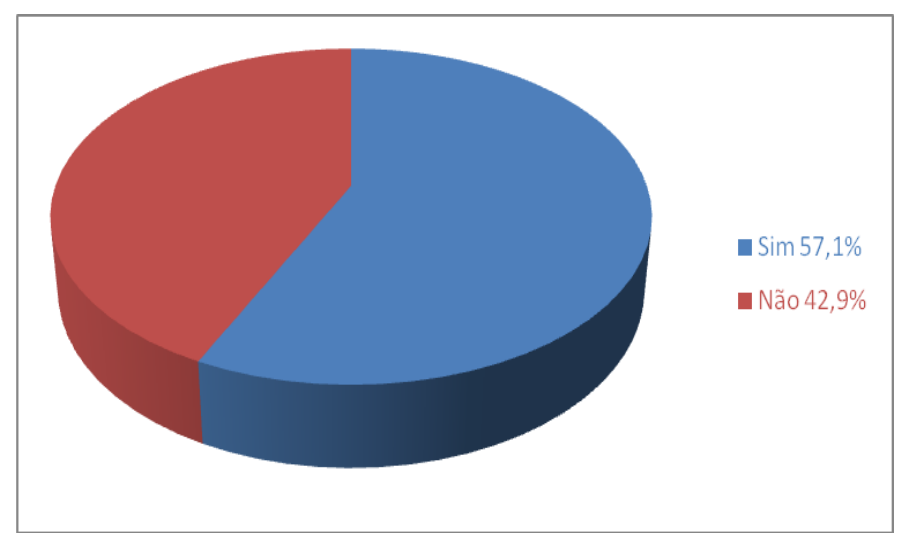

Fonte: Elaborado pelo Autor

c) Questão 3. De que forma o trabalhador usa o EPI? O trabalhador que tivesse respondido afirmativamente à questão anterior deveria descrever os equipamentos que usa em seu trabalho. Mais exatamente se faz uso completo, incompleto ou se não os usa. Apenas pouco mais de $24 \%$ dos mais de $57 \%$ que são orientados ao uso de EPI, utilizam todos os equipamentos. A maior parte $(42,8 \%)$ usa apenas parte do EPI e 33\% não usam (Figura 3). Além da carteira assinada, na lista dos principais itens vistoriados em fiscalização consta o uso de equipamentos de proteção individual (EPI). O empregador deve fornecer equipamentos de proteção individual e exigir seu uso pelo funcionário sob pena de infração (YONEYA, 2008).

Figura 3. Porcentagem de trabalhadores rurais orientados a usar EPI's, amostrados em cafezais do município de Ribeirão Corrente, SP, que usa todos os equipamentos de proteção individual, usa apenas parte dos equipamentos ou não usa os EPIs.



Fonte: Elaborado pelo Autor 
d) Questão 4. Sobre se o trabalhador percebe dificuldades para usar o EPI. Pretendia compreender o comportamento do trabalhador rural frente ao uso de EPI. Formulou-se a hipótese de que pudesse ocorrer algum tipo de rejeição. Partindo desse pressuposto, perguntou-se se ele percebia alguma dificuldade ao usá-lo. A maioria $(64,3 \%)$ dos trabalhadores que usam EPI não sente dificuldades na utilização dos equipamentos (Figura 4). Isso pode indicar que depois de orientados adequadamente, os funcionários compreendem a importância do uso desses equipamentos e não sentem dificuldades em utilizá-los.

Figura 4. Porcentagem de trabalhadores rurais amostrados em cafezais do município de Ribeirão Corrente, SP, que usam EPI’s e que sentem dificuldades ao usá-los.

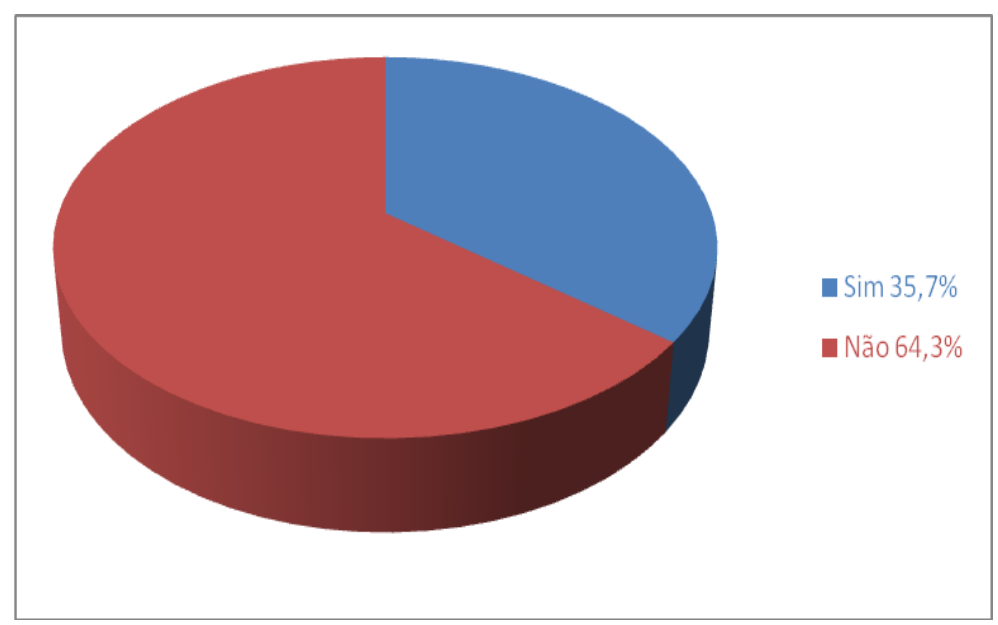

Fonte: Elaborado pelo Autor

e) Questão 5. Em caso de haver alguma dificuldade no uso dos equipamentos, é possível resolvê-la? Dos trabalhadores que relataram dificuldades no uso do EPI a sugestã mais recorrente para solucionar o problema (Figura 5) foi melhorar o EPI $(42,8 \%)$ em relação ao calor, $28,7 \%$ não vê como solucionar o problema e 7,1\% sugerem colocar cabine no trator. Segundo Yoneya (2008) o EPI fornecido pelo empregador inclui botina, luva, mangote de pano, óculos, touca árabe ou chapéu. Acessórios variam conforme o serviço. Durante a varrição do cafezal, por causa da poeira, é indicado o uso de máscara; os óculos protegem os olhos de galhos; se a área estiver "suja", com risco de presença de animais peçonhentos, a caneleira é item de segurança.

Figura 5. Sugestão dada por trabalhadores rurais amostrados em cafezais do município de Ribeirão Corrente, SP, que usam EPI's, sobre como resolver dificuldades no seu uso



Fonte: Elaborado pelo Autor 
f) Questão 6. Os trabalhadores pesquisados já ouviram falar da NR-31? Quanto ao conhecimento da NR31 (Figura 6) mais da metade dos trabalhadores entrevistados $(65,7 \%)$ desconhece essa norma, o que sugere que falta informação no campo.

Figura 6. Porcentagem de trabalhadores rurais amostrados em cafezais do município de Ribeirão Corrente, SP, que conhecem ou não a NR31.

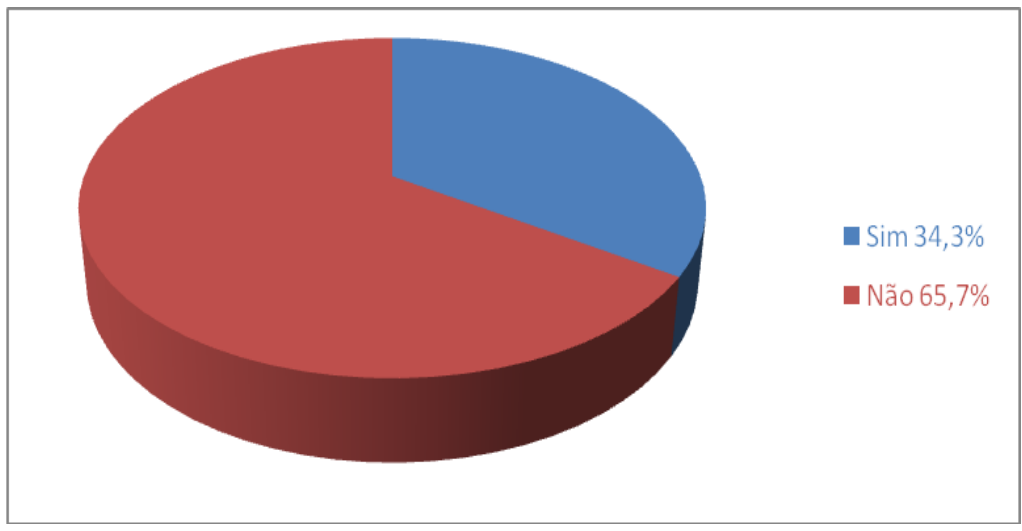

Fonte: Elaborado pelo Autor

g) Questão 7. Se os trabalhadores entrevistados sabiam se a empresa na qual trabalham cumpria a NR-31. De acordo com os dados da Figura 7, 42,8\% dos trabalhadores não sabe se o produtor cumpre ou não a NR31. O que novamente denota desconhecimento do assunto. Dos trabalhadores amostrados na pesquisa, $35,8 \%$ disseram que a propriedade não cumpre a norma e apenas $21,4 \%$ que a empresa cumpre a norma regulamentadora NR31.

Figura 7. Porcentagem de trabalhadores rurais amostrados em cafezais do município de Ribeirão Corrente, SP, que sabe se a empresa em que trabalha cumpre ou não a NR31.

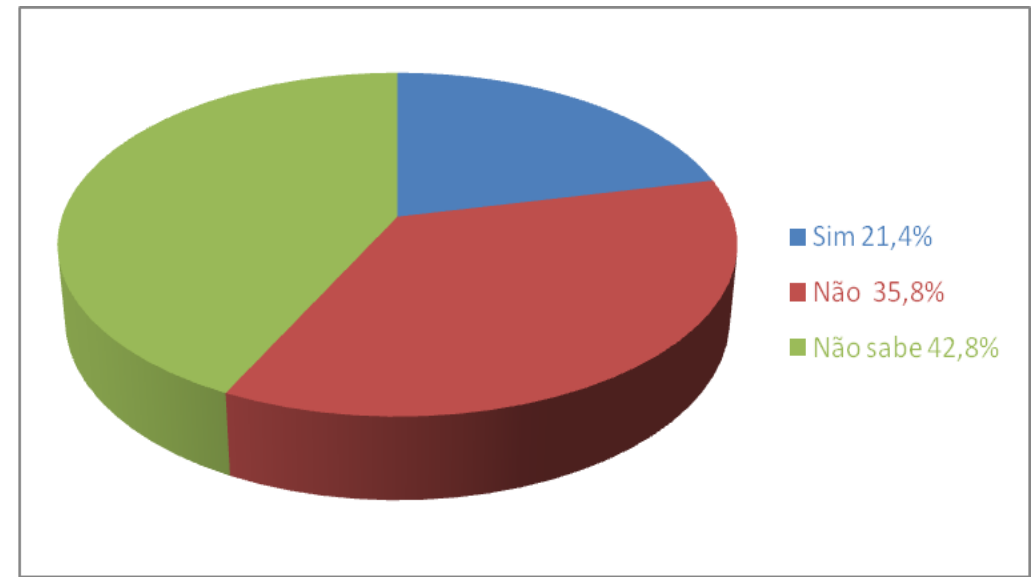

Fonte: Elaborado pelo Autor

\section{Segmento dos produtores}

Nas Figuras de 8 a 12 estão descritos os resultados levantados na pesquisa sobre os cafeicultores do município de Ribeirão Corrente, SP.

a) Questão 1. Escolaridade. O que predomina na escolaridade dos proprietários rurais (Figura 8) no município de Ribeirão Corrente, SP é o ensino fundamental incompleto (59,5\%), seguido de 16,2\% de ensino médio completo, apenas $2,7 \%$ são analfabetos, enquanto $8,1 \%$ possuem ensino fundamental 
completo e 5,4\% ensino médio incompleto. Não houve proprietários que possuíam ensino profissionalizante e ensino superior completo ou incompleto. A grande maioria dos produtores do município é pequeno proprietário em que a propriedade passa de pai para filho e tradicionalmente são produtores de café. A NR31 é uma norma complexa que merece uma forma mais didática de abordagem, a fim de facilitar a compreensão não só aos trabalhadores como também aos produtores, podendo dessa forma ser mais explorada e adequadamente cumprida.

Figura 8. Porcentagem de produtores rurais amostrados em cafezais do município de Ribeirão Corrente, SP, quanto ao grau de escolaridade



Fonte: Elaborado pelo Autor

b) Questão 2. Quanto à forma de colher o café. Pelos dados da Figura 9 observa-se que a colheita mista (manual e mecânica) é a predominante, perfazendo mais de 50\% das propriedades amostradas (51,4\%). A colheita exclusivamente manual ainda existe (27\%), mas já há propriedades em que se colhe apenas de forma mecanizada (21,6\%). Como relatado por Carvalho e Queiroz Neto (2006) o nível de exigência da NR 31 pode, inclusive, acelerar o processo de mecanização do trabalho no campo, servindo de estímulo à aquisição de colhedoras capazes de substituir o trabalho de 120 homens por dia.

Figura 9. Forma de colher o café, em cafezais amostrados do município de Ribeirão Corrente, SP.

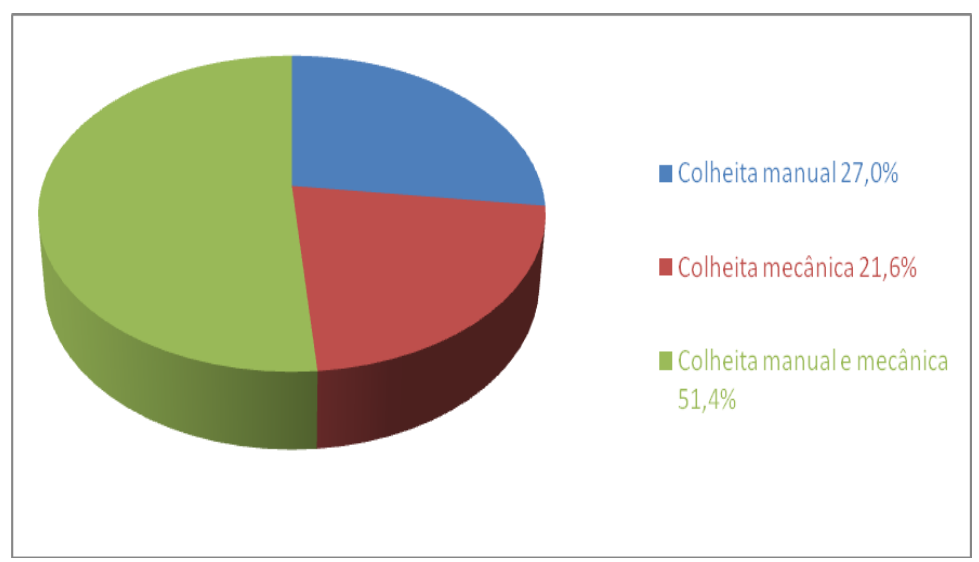

Fonte: Elaborado pelo Autor

c) Questão 3. Conhece a NR31? Assim como ocorre com os trabalhadores rurais, a maioria dos produtores entrevistados $(64,9 \%)$ não conhece a NR31 (Figura 10). Isso demonstra que é preciso que haja maior comunicação do setor técnico com o produtivo. Não é possível cobrar do empregador e empregado que se cumpra uma norma e até mesmo que se autue o produtor se esse está na ignorância. Carvalho e 
Queiroz Neto (2006) relatam que o Ministério do Trabalho e Emprego editou a Norma Regulamentadora Rural (NR) 31, que regula os procedimentos de segurança e saúde a serem observados no setor rural. Tal regulamento é o mais rígido do gênero existente no mundo. Extensa, a norma, que se prolonga por cerca de 30 páginas. Na teoria, o fundamento da norma é bastante nobre, mas na prática há grande polêmica em torno do tema, muitos produtores reclamam das fiscalizações realizadas com intuito punitivo e não para orientá-los, segundo Pereira (2006). De acordo ainda com o mesmo autor, muitas são as reclamações de cafeicultores que foram autuados, mas que não se consideram infratores, uma vez que vários parágrafos da norma são passíveis de mais de uma interpretação.

Figura 10. Porcentagem de produtores rurais amostrados em cafezais do município de Ribeirão Corrente, SP, que conhecem ou não a NR31.

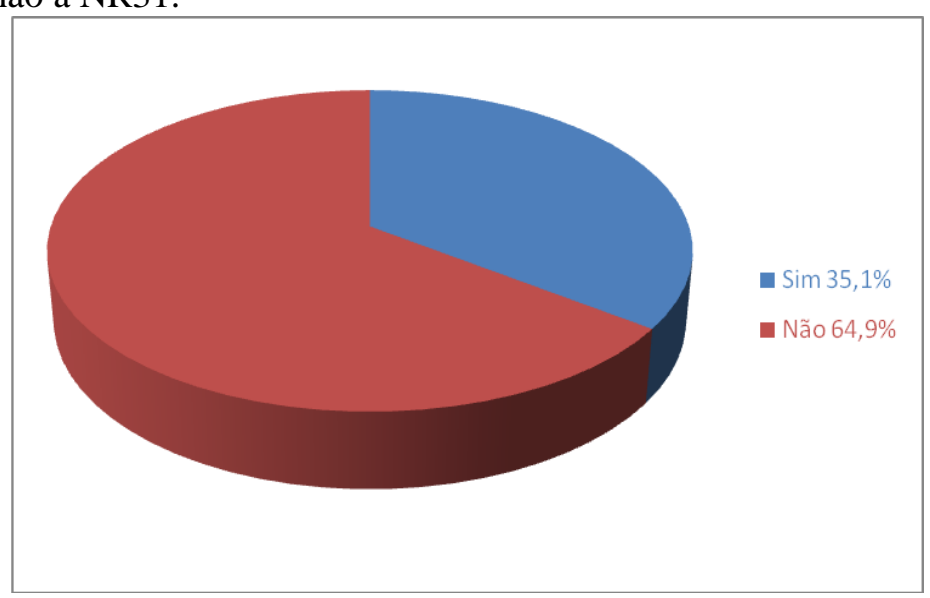

Fonte: Elaborado pelo Autor

d) Questão 4. Aplica a NR 31? Como verificado (Figura 11) a maioria dos produtores não conhece a norma $(64,8 \%)$ e se a conhecem não a aplicam $(21,6 \%)$. Apenas $10,9 \%$ conhecem a norma, mas a aplicam parcialmente. Apenas $2,7 \%$ dos entrevistados aplicam integralmente a NR31. Verifica-se, então, que o percentual de produtor que aplica a NR 31 é muito pequeno.

Figura 11. Porcentagem de produtores rurais amostrados em cafezais do município de Ribeirão Corrente, SP, que aplicam ou não a NR31.



Fonte: Elaborado pelo Autor

e) Questão 5. Se você aplica a NR31 integralmente, qual a dificuldade para colocar a norma em prática? Os mesmos 2,7\% dos produtores que cumprem integralmente a NR31 (Figura 11) disseram 
não ter nenhuma dificuldade para colocá-la em prática (Figura 12). Era esperado que os produtores relatassem problemas como não uso de EPI pelos funcionários, custos, exigências, dificuldades, mas o que se constata é que a maior dificuldade é não conhecer bem a norma, pois quem a conhece e aplica não relata dificuldades.

Figura 12. Porcentagem de produtores rurais amostrados em cafezais do município de Ribeirão Corrente, SP, que aplicam integralmente a NR31 e tem ou não dificuldade para colocar a norma em prática.

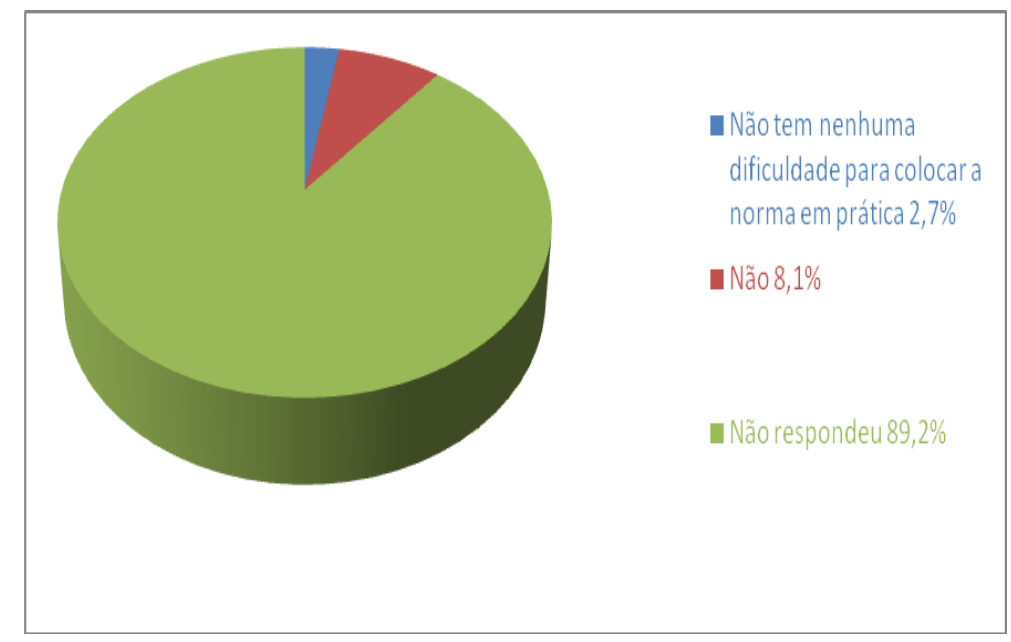

Fonte: Elaborado pelo Autor

Ao analisar todos os dados da pesquisa feita no município de Ribeirão Corrente/SP, verifica-se que mesmo em propriedades predominantemente pequenas e em locais de relevo muitas vezes não favorável, a mecanização da colheita é grande e a colheita exclusivamente manual, já é reduzida (27\%). Há um grande desconhecimento da NR 31 por parte dos proprietários e consequentemente dos empregados. Percebe-se que isso se deve a alguns fatores como: complexidade da norma, falta de divulgação mais didática, baixa escolaridade do proprietário. Por não terem conhecimento e interesse em seguir a NR 31, esta não é transmitida aos empregados. O pequeno percentual de proprietários que usam integralmente a NR31 não relata dificuldades para colocá-la em prática. Assim como acontece com a norma NR31, também o uso do EPI é pequeno e os trabalhadores queixam-se do calor. Outro dado que chama a atenção é o número alto de empregados rurais sem registros em carteira, o que denota que a atividade cafeeira ainda é feita em descompasso com as normas trabalhistas.

\section{CONCLUSÃO}

É grande o desconhecimento da NR 31 pelos cafeicultores e trabalhadores rurais do município de Ribeirão Corrente, SP, sendo essa a maior dificuldade em implantar e consequentemente manter a NR31. Também é baixo o uso de EPI nas propriedades rurais e a maior queixa dos trabalhadores é o calor.

\section{REFERÊNCIAS}

CARVALHO, L.C.; QUEIROZ NETO, C.V. Crise e rigidez de normas elevam desemprego rural. Artigo publicado originalmente no Informativo Técnico Revista Gleba / n. 218, ano 2006, nov./dez. Disponível em: http://www.cafepoint.com.br/cadeia-produtiva/espaco-aberto/crise-e-rigidez-de-normaselevam-desemprego-rural-33070n.aspx . Acesso em: 05 maio 2011. 
CONTAG - Confederação Nacional dos Trabalhadores na Agricultura. Norma regulamentadora Específica para a Área Rural. PORTARIA No 86, DE 03 DE MARÇO DE 2005 - Diário Oficial da União (DOU) de 04/03/05). Disponível em: http://www.contag.org.br/imagens/Assalariados/Ass-NR-31Especifica- AreaRural.pdf . Acesso em: 30 maio 2011.

DINAMARCO, J.F. A Exigente NR31. Revista Idea News, ano 5, n. 62, dez./2005. Disponível em: http://www.revistaideanews.com.br/ . Acesso em: 13 mar. 2011.

Guia Trabalhista. Disponível em: http://www.guiatrabalhista.com.br/legislacao/nrs.htm . Acesso em: 21 mar. 2011.

PEREIRA, S.P. NR31 gera polêmica no campo. CCCRJ. Revista do Café. 2009. Disponível em: http://www.peabirus.com.br/redes/form/post?topico_id=16278 Acesso em: 02 maio 2011.

SÃO PAULO (Estado). Secretaria de Agricultura e Abastecimento. Coordenadoria de Assistência Técnica Integral. Instituto de Economia Agrícola. Levantamento censitário de unidades de produção agrícola do Estado de São Paulo - LUPA 2007/2008. São Paulo: SAA/CATI/IEA, 2008. Disponível em: http://www.cati.sp.gov.br/projetolupa . Acesso em: 15 maio 2011.

YONEYA, F., Colheita do café: mão-de-obra em dia com a lei. O Estado de S.Paulo. Tópicos: Suplementos, Agrícola 23/07/2008. Disponível em:

http://www.revistacafeicultura.com.br/index.php?tipo=ler\&mat=16694 . Acesso em: 02 maio 2011. 